\title{
LUNG FUNCTION IN YOUNG SRI LANKAN FEMALES
}

\author{
M. UDUPIHILLE \\ Department of Pbysiology, Faculty of Medicine, University of Peradeniya, \\ Peradeniya, Sri Lanka. \\ (Date of receipt : 02 August 1988) \\ (Date of acceptance 23 September 1988)
}

\begin{abstract}
A study of respiratory function was carried out in 192 adult Sri Lankan females of age group $19-29$ years. Vital capacity (VC), Forced vital capacity (FVC), forced expiratory volume in one second $\left(F E V_{1}\right)$ and maximum voluntary ventilation $\left(M \bar{V} V_{F}\right)$ were measured by spirometry and the peak flow rate by a mini Wright peak flow meter. The values observed were found to be less than that reported for Europeans and closer to those of North Indian populations. The relationship of the results to height and weight was studied. Prediction formulae based on height were derived for some of the tests.
\end{abstract}

\section{Introduction}

Measurement of lung function is widely used in the diagnosis and the assessment of progress in patients with cardiopulmonary disease and evaluating the fitness of patients to undergo anaesthesia. Therefore it is important to determine reference ranges for the Sri Lankan population who vary significantly in stature from their European counterparts. Cullumbine's islandwide survey of physical fitness in 1949 states that females of average age and height had a mean vital capacity of $1570 \mathrm{ml}$. These data are significantly lower than those of $\mathrm{Koch}^{6}$ where the vital capacity of young adult females was reported as $2160 \mathrm{ml}$. The fact that Koch's study group consisted of University freshmen of a presumably higher socio-economic status may account for this difference.

The above figures are much lower than those reported for European countries. Kaltreider, et al $^{5}$ reported a vital capacity(VC) of $3.14 \pm 0.411$ for females of age $23.1 \pm 3.4$ years. They were taller $(163.4 \pm 4.2 \mathrm{~cm})$ and heavier $(57.2 \pm 9.4 \mathrm{~kg})$ than Sri Lankan females of the same age group. This greater stature may account for the larger vital capacities observed. In this respect, Sri Lankans are closer to Indian populations and it would be more relevant to compare Indian figures with the available Sri Lankan figures. Young North Indian females of age group 15-40 years have a vital capacity of $26251^{4}$ and South Indians of age group 17-29 years have a mean vital capacity of $25601 .^{8}$ They are significantly higher than those reported for a comparable age group by Koch. ${ }^{6}$ A preliminary study ${ }^{9}$ of Sri Lankan females of age range 19-29 years gave a value of $2698 \pm 555.6 \mathrm{ml}$ for vital capacity.

Vital capacity has been related to several body measurements such as body surface area, thoracic volume, body weight, height and age. Prediction formulae have been worked out from these relationships for European populations. The purpose of this study is to examine the relationship of lung 
function tests to body height and weight and to obtain prediction formulae based on these relationships for young Sri Lankan females.

\section{Experimental}

\subsection{Subjects}

192 females of age range $19-29$ years were studied. The subjects were selected from among medical students and staff of the University of Peradeniya. They had no history of cardiopulmonary illness in the past or at the time of examination. Height and weight of each subject were measured using a standard laboratory scales (Detectomedic, Detecto scales INC, Brooklyn, N.Y., USA).

\subsection{Spirometric Measurements}

Spirometric measurements were carried out by the methods described previously for adult males. ${ }^{9}$ The measurements were vital capacity (VC), forced vital capacity (FVC), forced expiratory volume in one second ( $F E V_{1}$ ), maximum voluntary ventilation $\left(\mathrm{MVV}_{\mathrm{F}}\right)$, and peak expiratory flow rate (PEF). The terminology for lung function tests put forward by Gandevia and Hugh-Jones ${ }^{3}$ was used in this study.

\section{Results}

A total of 192 females of mean age $22.07 \pm 2.27$ years was studied.

Table 1 gives the means and standard deviations of results. All data were expressed at BTPS.

Table 1. Means and Standard Deviations of Results $(n=192)$

\begin{tabular}{llll}
\hline Age(years) $22.1 \pm 2.3$ & FVC $(\mathrm{ml})$ & $2435.7 \pm 437.9$ \\
Height $(\mathrm{cm})$ & $156.6 \pm 6.2$ & $\mathrm{FEV}_{1}(\mathrm{ml})$ & $2354.4 \pm 405.9$ \\
Weight $(\mathrm{kg})$ & $45.4 \pm 6.3$ & $\mathrm{MVV}_{\mathrm{F}}(\mathrm{ml})$ & $673.5 \pm 18.6$ \\
Vital capacity $(\mathrm{ml}) \quad 2574.6 \pm 462.2$ & $\operatorname{PEF}(1 / \mathrm{m})$ & $428.9 \pm 77.4$ \\
\hline
\end{tabular}
vious data. ${ }^{1}$

Results obtained for height and weight compare favourably with pre-

A matrix of bi-variate correlation coefficients was developed to study the relationship between the different body measurements and is shown in Table 2. Height was seen to have a highly significant correlation with weight, VC, FVC, FEV 1 and PEF, as indicated by high values of $r$. Relationship of the above measurements to weight were seen to be of a lower order although significant as indicated by lower $r$ values. The magnitude of these $r$ values indicate that less than $25 \%$ of the variation in results could be accounted 
for by changes in weight. Therefore height was chosen as the parameter to derive prediction formulae for the other five measurements.

Table 2. Measurement of physical characteristics and pulmonary function Correlation coefficients $(n=192)$

\begin{tabular}{|c|c|c|c|c|c|c|c|}
\hline & $\begin{array}{l}\text { Height } \\
\text { (com) }\end{array}$ & $\begin{array}{c}\text { Weight } \\
(\mathbf{k g})\end{array}$ & $\begin{array}{l}\text { VC } \\
(\mathrm{ml})\end{array}$ & $\begin{array}{l}\text { FVC } \\
\text { (ml) }\end{array}$ & $\begin{array}{c}\mathrm{FEV}_{1} \\
(\mathrm{ml})\end{array}$ & $\begin{array}{l}M V V_{F} \\
(1 / m)\end{array}$ & $\begin{array}{l}\text { PEF } \\
(1 / \mathrm{m})\end{array}$ \\
\hline Height: & & $0.5800^{*}$ & $0.6006^{*}$ & $0.4547^{*}$ & $0.4412^{*}$ & 0.1087 & $0.4452^{*}$ \\
\hline Weight & & & $0.5048^{*}$ & $0.5814^{*}$ & $0.3509^{*}$ & 0.0865 & $0.2624+$ \\
\hline$\overline{\mathrm{VC}}$ & & & 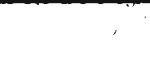 & $0.7577^{*}$ & $0.7349^{*}$ & $0.2184+$ & $0.4920^{*}$ \\
\hline FVC & & & $\therefore$ & & $0.8884^{*}$ & $0.2771+$ & $0.3328^{*}$ \\
\hline $\mathrm{FEV}_{1}$ & & & & & . & 0.2230 & $0.3810^{*}$ \\
\hline$M B C$ & & & & & & & 0.1007 \\
\hline
\end{tabular}

$* \mathrm{p}<0.001$

$+\mathrm{p}<0.01$

Regression equations are given below.

$$
\begin{array}{lll}
\text { VC } & & =-4403.2+42.12 \mathrm{H}(\mathrm{r}=0.60) \\
\text { FVC } & & =-2347.3+30.97 \mathrm{H}(\mathrm{r}=0.46) \\
\text { FEV }_{1} & & =-2201.7+28.85 \mathrm{H}(\mathrm{r}=0.44) \\
\text { PEF } & =-439.4+5.61 \mathrm{H}(\mathrm{r}=0.45) \\
& & \\
& &
\end{array}
$$

As $M V V_{F}$ did not show a high correlation with either height or weight, it was not possible to calculate a prediction formula for these measurements.

\section{Discussion}

The results of lung function tests in the present study are lower than those reported for many Western populations. They are closer to values available for North Indian women reported by Jain and Ramiah. ${ }^{4}$ Peak expiratory flow rate too seem to be close to North Indian figures. 
Values for maximum voluntary ventilation did not correlate with height or weight. $M V V_{F}$ depends more on factors such as compliance of the lungs and the thoracic wall and the efficiency of the respiratory muscles than on body size. This may account for the poor relationship observed with height and weight. An earlier study ${ }^{9}$ showed the same lack of correlation between height and weight and $\mathrm{MVV}_{\mathrm{F}}$ in the case of males. Therefore it was not possible to derive a prediction formula for this value.

The present survey gives higher values for vital capacity than in Koch's study $^{6}$ which reported a value of $2160 \mathrm{ml}$ in the case of females. It is difficult to account for this difference as both groups of subjects were of similar socio-economic backgrounds.

\section{Acknowledgements}

The author thanks Messers D. R. Attapattu and R. A. D. Nicholas for assistance with spirometry and Miss Rupika Perera for assistance with statistical analysis.

\section{References}

1. BALASURIYA, P. (1984) Height and weight measurements of medical and dental students at University of Peradeniya (abstract) Proc. of the Kandy Society of Medicine, $7: 38$.

2. CULLUMBINE, H. (1949) Some health statistics for the Ceylonese. Cey. J. med Sci. (D), $6: 1$.

3. GANDEVIA B. \& HUGH-JONES, (1957) Terminology for measurements of ventilatory capacity. Thorax $12: 290$.

4. JAIN, S.T. \& RAMIAH, T.J. (1967) Spirometric studies in healthy women of $15-40$ years age. Ind. $J$. chest Diseases, $9: 1$.

5. KALTRIDER, N.L., FRAY, W.W. \& HYDE, H.V. (1938) The effect of age on the total pulmonary capacity and its subdivisions. Am. Rev. resp. Dis. $37: 662$.

6. KOCH, A.C.E. (1954) The vital capacity of University students. Cey. J. med Sci. $6: 1$.

7. MALIK, S.K., JINDAL, S.K., BANGA, N., SHARDA, P.K. \& GUPTA, H.D. (1980) Peak expiratory flow rate of healthy North Indian teachers. Ind. J. med. Res. $71: 322$.

8. SINGH, H.D. \& PRABHAKARAN3. (1957) Pulmonary function studies. J. Ind. med. Assn. $29: 269$.

9. UDUPIHILLE, M. \& KARALLIEDDE, L.D. (1985) Pulmonary function in Sri Lankan adults. Cey: med J. 30 : 103. 